\title{
Electron cyclotron resonance plasma and thermal oxidation mechanisms of germanium
}

\author{
Y. Wang, Y. Z. Hu, and E. A. Irene \\ Department of Chemistry, University of North Carolina, Chapel Hill, North Carolina 27599-3290
}

(Received 24 December 1993; accepted 14 April 1994)

\begin{abstract}
The electron cyclotron resonance (ECR) plasma oxidation and thermal oxidation mechanisms for germanium were investigated using in situ spectroscopic and single wavelength ellipsometry. ECR plasma oxidation was performed at substrate temperatures of $80-400^{\circ} \mathrm{C}$ while thermal oxidations were performed berween 400 and $600^{\circ} \mathrm{C}$. Optical modeling shows that there is an interface between the oxide film and the substrate that is composed of germanium oxide and amorphous germanium. Fourier transform infrared and $x$-ray photoelectron spectroscopy data confirm that the oxides resulting from thermal and $\mathrm{ECR}$ plasma oxidation are $\mathrm{GeO}_{2}$. The real time oxidation analysis shows that both kinds of oxidation of Ge follow linear-parabolic kinetics, and yield temperature activated transport. The activation energy for ECR plasma oxidation is about one order smaller than that of thermal oxidation. This indicates different oxidation species. Less charge was formed at the interface for ECR plasma oxides.
\end{abstract}

\section{INTRODUCTION}

Low temperature processing of integrated circuits is of interest, since rates for thermally activated defect production and redistribution of dopants are greatly reduced. Recently low temperature processing techniques ${ }^{1,2}$ have yielded remarkable dielectrics that might one day replace conventional thermal oxidation. Among these techniques electron cyclotron resonance (ECR) plasma offers many important advantages ${ }^{3,4}$ for low damage semiconductor processing, including low ionic energies, high ionization efficiency, low pressure and low temperature operation. Oxygen ECR plasmas have been used to grow $\mathrm{SiO}_{2}$ from single crystal $\mathrm{Si}^{5-8}$ exhibiting physical, chemical, and electrical properties similar to those of thermal oxide.

Germanium is an attractive candidate semiconductor for microelectronic technology, ${ }^{9-11}$ because the mobility of holes in $\mathrm{Ge}$ is larger than any of the other common semiconductors, and the hole and electron mobilities are much less disparate than in other semiconductors. However, it is important to be able to grow a high quality insulator film on the Ge surface in particular at low temperature to avoid the interface decomposition of the oxide, and ECR plasma oxidation of $\mathrm{Ge}$ is a candidate to provide a useful process.

In a previous spectroscopic ellipsometry study ${ }^{12}$ we reported the $\mathrm{GeO}_{2}$ film dielectric function from thermally grown $\mathrm{GeO}_{2}$ films, and ECR plasma oxidation kinetics of Ge. ${ }^{13}$ In the present study both ECR plasma and thermal oxidation of Ge were investigated and compared with respect to the similarities and differences in the oxidation mechanisms, the interface between the oxide and the substrate, and some preliminary electronic properties. In situ real-time single wavelength ellipsometry (SWE) was used during oxidation, and in situ static spectroscopic ellipsometry (SE) was performed at various times inside the process vacuum chamber. In order to understand the $\mathrm{Ge}-\mathrm{GeO}_{2}$ interface, some $e x$ situ analyses were also performed. Electronic properties were examined using high frequency capacitance-voltage $(C-V)$ measurement; $\mathrm{x}$-ray photoelectron spectroscopy (XPS) was used to establish the chemical species; and transmission Fourier transform infrared (FTR) spectroscopy was performed to determine the molecular structure.

\section{EXPERIMENTAL PROCEDURES}

In this study both low pressure ECR plasma oxidations and $1 \mathrm{~atm}$ thermal oxidations were done in the same apparatus that was described previously. ${ }^{14,15}$ The system consists of a homebuilt high precision rotating analyzer spectroscopic ellipsometer and an independent vacuum processing chamber equipped with a homemade ECR plasma source. 2.45 $\mathrm{GHz}$ microwaves, as generated by a magnetron, were guided through a quartz window to the ECR plasma chamber into which pure oxygen gas $(99.997 \%$ ) could be flowed. The vacuum chamber can be evacuated to $1 \times 10^{-7}$ Torr using a turbomolecular pump. The Ge substrate to be oxidized is placed on a stainless-steel holder that can be heated using a halogen lamp. The temperature was monitored and controlled using a thermocouple attached to the front side of the holder and adjacent to the sample. A calibration of the holder temperature was made both in comparison with wafer temperature in vacuum for ECR plasma oxidation, and at atmospheric pressure for thermal oxidation.

Samples used were commercially available $n$-type (100) Ge wafers (resistivity: $20 \Omega \mathrm{cm}$ ). All substrates were subjected to a cleaning procedure as described by Aspnes, ${ }^{16}$ which consists of $0.05 \mathrm{vol} \%$ bromine in methanol etching, followed by a buffered HE cleaning step, and a final deionized water rinsing. ECR plasma oxidation conditions were as follows: total pressure of $1 \times 10^{-3}$ Torr, oxygen flow rate of $20 \mathrm{sccm}$, microwave power of $300 \mathrm{~W}$, substrate temperature from 25 to $400^{\circ} \mathrm{C}$, and substrate bias voltage from 0 to +60 $\mathrm{V}$.

The oxide growth was monitored by in situ real-time single wavelength ellipsometry (SWE). Various thicknesses reported in this work were obtained by a trajectory method using a single film model. ${ }^{17,18}$ The single wavelength chosen for Ge is $335 \mathrm{~nm}$, because at this wavelength the measure- 
TABLF I. The best fit optical model results for typical thermal and ECR plasma oxidation conditions. $L_{\mathrm{ox}}$ is the top oxide layer tivickness. $L_{\text {int }}$ is the interface layer thickness. $a-\mathrm{Ge} \%$ is the volume percentage of amorphous germanium in the interface layer. $\delta$ is the unbiased estimator.

\begin{tabular}{lrrrrr}
\hline Oxidation conditions & \multicolumn{1}{c}{$L_{\mathrm{ax}}(\mathrm{nm})$} & $L_{\text {int }}(\mathrm{nm})$ & $a-\mathrm{Ge} \%$ & $\delta \times 10^{3}$ \\
\hline $\begin{array}{l}\text { Thermal } \\
\text { oxidation }\end{array}$ & $400^{\circ} \mathrm{C}, 120 \mathrm{~min}$ & $1.62 \pm 0.60$ & $1.43 \pm 0.51$ & $27 \pm 28$ & 4.72 \\
& $500^{\circ} \mathrm{C}, 125 \mathrm{~min}$ & $15.56 \pm 0.85$ & $2.09 \pm 0.44$ & $47 \pm 29$ & 7.89 \\
& $550^{\circ} \mathrm{C}, 120 \mathrm{~min}$ & $25.35 \pm 0.88$ & $4.76 \pm 0.27$ & $30 \pm 8$ & 7.7 \\
& & & & & \\
ECR plasma & $100^{\circ} \mathrm{C}, 300 \mathrm{~W},+60 \mathrm{~V}$ bias, $70 \mathrm{~min}$ & $3.77 \pm 0.21$ & $2.28 \pm 0.16$ & $49 \pm 4$ & 4.58 \\
oxidation & $300^{\circ} \mathrm{C}, 300 \mathrm{~W},+30 \mathrm{~V}$ bias, $30 \mathrm{~min}$ & $10.19 \pm 0.09$ & $2.15 \pm 0.09$ & $45 \pm 7$ & 4.62 \\
& $400^{\circ} \mathrm{C}, 300 \mathrm{~W}+60 \mathrm{~V}$ bias, $40 \mathrm{~min}$ & $16.92 \pm 0.07$ & $0.82 \pm 0.08$ & $31 \pm 24$ & 6.19 \\
\hline
\end{tabular}

ments are insensitive to temperature and very sensitive to oxide growth. ${ }^{19}$ Spectroscopic ellipsometry (SE) measurements were taken at 51 photon energies between 2.0 and 4.5 $\mathrm{eV}$, which include two interband transition at 2.3 and $4.4 \mathrm{eV}$. The SE measurements were taken with the samples inside the vacuum chamber after ECR plasma (or thermal) oxidation. For oxides grown above room temperature, the spectra were obtained after cooling to room temperature.

Thermal oxidations were carried out at $1 \mathrm{~atm}$ in pure $\mathrm{O}_{2}$ in the same system, but without microwave plasma operation through the use of a high vacuum valve between the processing chamber and the turbomolecular pump. Oxygen fiow rate was $150 \mathrm{sccm}$. Substrate temperatures were from 400 to $550^{\circ} \mathrm{C}$. After a cleaned Ge substrate was loaded in the vacuum chamber, the substrate temperature was raised in vacuum. When the substrate reached the desired temperature, the high vacuum valve between processing chamber and the turbomolecular pump was closed. Real-time SWE commenced and then oxygen was admitted into the processing chamber. Upon completion of an oxidation experiment the system was evacuated and SE was performed after cooling the sample to room temperature.

The FTIR technique that we used was discussed by Zettler et al. ${ }^{20}$ wherein IR transmission measurements were carried out at a $75^{\circ}$ incident angle with $p$-polarized light using a Fourier-transform infrared spectrometer. Double side polished Ge wafers were used. After ECR plasma or thermal oxidation of $\mathrm{Ge}$, an IR reflective aluminum film was vacuum evaporated on the oxide overlayer to enhance the IR response. The IR measurement was executed with light incident from backside of the wafer. A spectrum taken from an aluminum mirror using the same setup provided the background spectrum. The transmission spectra were measured in the wave number region between 400 and $2000 \mathrm{~cm}^{-1}$.

$\mathrm{Au} / \mathrm{GeO}_{2} / \mathrm{Ge}$ MOS structures were prepared for $\mathrm{C}-\mathrm{V}$ measurements. Following oxidation, metal gates, $9 \times 10^{-4}$ $\mathrm{cm}^{2}$ in area, were deposited through a shadow mask by evaporating $\sim 1000 \AA$ of $A u$ at $2 \AA / s$ under a base pressure of $1 \times 10^{-7}$ Torr. All the samples received a post metalization anneal at $400^{\circ} \mathrm{C}$ in $\mathrm{Ar}$ for $30 \mathrm{~min}$. Contact was made to the gate with a tungsten probe. Backside contact was made by abrading the wafer and applying a GaIn paste. The $1 \mathrm{MHz}$ high frequency $C-V$ measurements were automated, and interfaced to a personal computer for data acquisition and analysis. $^{21}$

\section{EXPERIMENTAL RESULTS}

\section{A. Optical modeling}

The ellipsometric measurement yields two angles $\Delta$ and $\Psi$, from which the complex reflection ratio $\rho_{\exp }$ is obtained: $\rho_{\exp }=\tan \Psi e^{i \Delta}$. From a literature database for the known constituents of the film and substrate, $\rho_{\text {cal }}$ is calculated and compared with $\rho_{\mathrm{exp}}$. An unbiased estimator $\delta$ is calculated from the relationship: ${ }^{17,22}$

$$
\delta=\left(\frac{1}{N-P-1} \sum_{i=1}^{N}\left|\rho_{\exp }-\rho_{\mathrm{cal}}\right| 2\right)^{1 / 2},
$$

where $N$ is the number of wavelengths samples, and $P$ the number of unknown parameters. A minimizing procedure gives the best fit parameter which are film thickness and volume percentage for the constituents at the $90 \%$ confidence level. Previous studies ${ }^{13}$ have shown that a two layer model, composed of pure $\mathrm{GeO}_{2}$ as the top layer with a thickness of $L_{\mathrm{ox}}$, and an interface layer composed of $\mathrm{GeO}_{2}$ and $a$-Ge with a thickness of $L_{\text {int }}$, yields the best fit in terms of the lowest $\delta$. Compared to a pure $\mathrm{GeO}_{2}$ single layer model, the two layer model provides significant improvements of unbiased estimator, often by a factor of 3 times.

Table I shows the best fit model results for typical thermal and ECR plasma oxidation conditions as measured by spectroscopic ellipsometry. For thermal oxidation between 400 and $550^{\circ} \mathrm{C}$, there is always a distinct interface layer for different oxidation temperatures and different oxide thicknesses. For ECR plasma oxidation at low temperature, the interface is also clear; but the interface becomes very thin $(<1 \mathrm{~nm})$ when the substrate temperature was raised to $400^{\circ} \mathrm{C}$

\section{B. ECR plasma and thermal oxidation kinetics}

In order to investigate oxidation kinetics, real time SWE was used to monitor the oxide film growth. Figures 1(a) and 1(c) show the evolution of oxide thickness as a function of oxidation time at different temperatures during the first 20 min of thermal and ECR plasma oxidation, respectively. The data were obtained from real-time SWE measurements analyzed using a single layer model. Figures $1(b)$ and $1(d)$ are similar results but were obtained by SE using the two layer model. The total thicknesses $\left(L_{\mathrm{ox}}+L_{\mathrm{in}}\right)$ are given by the 

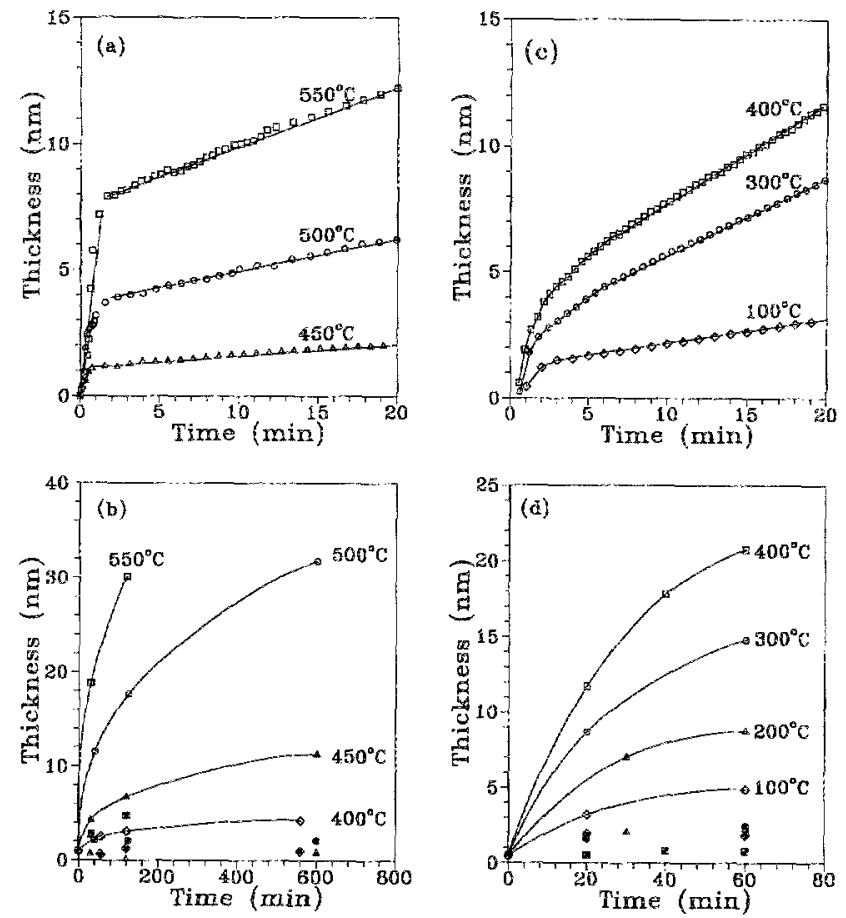

Fig. 1. Oxide thickness vs oxidation time at different temperatures. (a) and (b) are for thermal oxidation while (c) and (d) are for ECR plasma oxidation at $+60 \mathrm{~V}$ bias. (a) and (c) were obtained from real-time SWE measurements and using a single layer model; (b) and (d) are similar results but were obtained by $S E$ using the two layer model. The total thicknesses are given by the solid lines through the data and the interface thickness by the filled symbols.

solid line and the interface thickness $\left(L_{\text {int }}\right)$ by the filled symbols. The results shown in Fig. I(b) were obtained from thermal oxidation in a conventional oxidation furnace. ${ }^{23}$ Any temperature differences for the two systems were well within $5^{\circ} \mathrm{C}$. For both thermal and ECR plasma oxidation there are three regimes for the relationship between oxide thickness and oxidation time, as we had previously reported. ${ }^{13}$ : two linear and one parabolic.

For thermal oxidation the second linear and the parabolic regimes are in agreement with the model developed by Deal and Grove $(D G),{ }^{24}$ which is summarized with the following rate equation: ${ }^{25}$

$$
\frac{L^{2}-L_{0}^{2}}{k_{P-D G}}+\frac{L-L_{0}}{k_{L-D G}}=t-t_{0}
$$

where $k_{p-\mathrm{DG}}$ and $k_{l-\mathrm{DG}}$ represents the parabolic and linear rate constants in DG model, respectively. $k_{P-D G}$ is related to diffusion through the oxide while $k_{L-\mathrm{DG}}$ reflects the reaction at the Ge surface. The constants $L_{0}$ and $t_{0}$ are offsets to the DG model which account for an initial region not explained by the DG model. In the DG model $k_{P-D G}$ corresponds to an elementary, thermally activated diffusion process obeying Boltzman statistics and described by an Arrhenius equation of the form

$$
k_{P-\mathrm{DG}}=k_{0} \exp \left(-E_{a} / k_{B} T\right),
$$
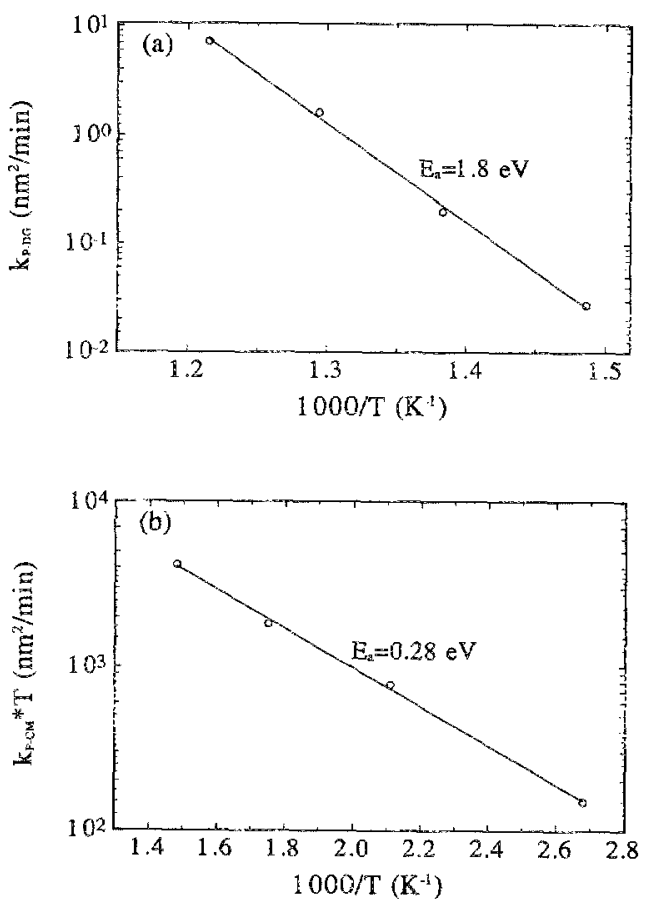

Fici 2. Arrhenius plots of the parabolic coefficients for (a) thermal and (b) ECR plasma oxidation.

where $k_{B}$ is the Boltzman constant, $T$ is the oxidation temperature, and $E_{a}$ is the activation energy. The liner Arrhenius plot for $k_{P-\mathrm{D} O \mathrm{G}}$ is shown in Fig. 2(a) and yield an activation energy of $1.8 \mathrm{eV}$.

The ECR plasma oxidation, the oxide growth in the first linear region is very fast and virtually bias independent. The parabolic region fits the Cabrera-Mott (CM) model, ${ }^{26}$ which considers oxidation by charged species in the limit of a low electric field and is given by the relation

$$
L_{\mathrm{ox}}^{2}=C_{1} \exp \left(-\frac{E_{a}}{k_{B} T}\right) \frac{V_{\mathrm{ax}}}{k_{B} T} t+C_{2},
$$

where $V_{o x}$ is the potential drop across the oxide film, $E_{c i}$ is the thermal activation energy associated with the diffusion of oxidizing species in the applied electric field, $t$ is oxidation time, $k_{B}$ is the Boltzman constant, $T$ is the oxidation temperature, and $C_{1}$ and $C_{2}$ are constants. The parabolic coefficient $k_{P \text {-CM }}$ is given as

$$
k_{P-\mathrm{CM}}=C_{1} \exp \left(-\frac{E_{a}}{k_{B} T}\right) \frac{V_{o x}}{k_{B} T},
$$

where $k_{P \text {-CM }}$ is approximately iner with bias voltage. The increase of the growth rate with the positive bias on Ge wafer indicates that the negative oxygen ions are the principle oxidant species. ${ }^{13}$ In the $\mathrm{CM}$ model the parabolic coefficient also follows an Arrhenius expression, and the activation energy calculated from Fig. 2(b) is $0.28 \mathrm{eV}$.

\section{FTIR measurements}

Figures 3(a) and 3(b) show typical FTIR spectra for thermal and ECR plasma oxidized samples, with the main $a b-$ 


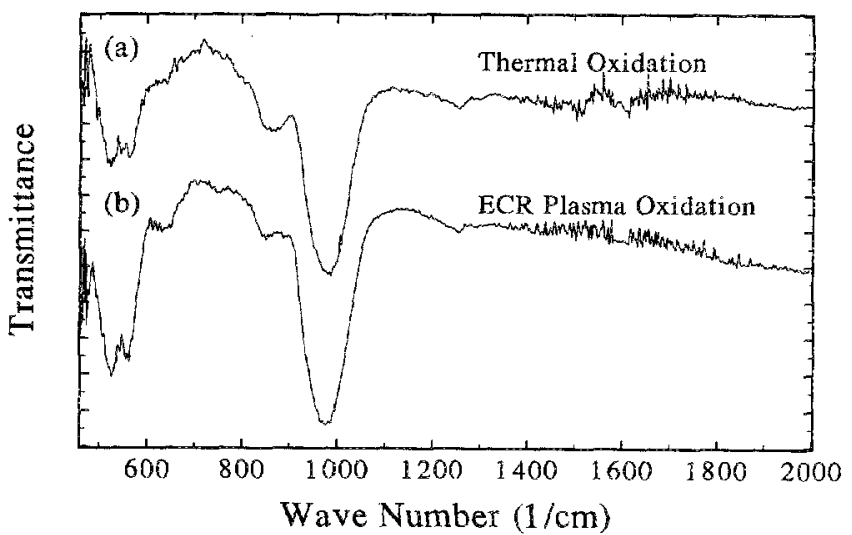

FK. 3. FTIR spectra of typical (a) thermal oxide at $550^{\circ} \mathrm{C}$; (b) ECR plasma oxide at $+60 \mathrm{~V}$ bias and $400^{\circ} \mathrm{C}$ grown on $c$-Ge substrates.

sorption peak positions summarized in Table II. The vibrational bands observed in thermal oxide samples are associated with Ge-O-Ge stretching modes (981 and 859 $\mathrm{cm}^{-1}$ ) and bending modes (563 and $521 \mathrm{~cm}^{-1}$ ) and are in agreement (slightly shifted but with all main spectral features) with results from the literature. ${ }^{27-29}$ The IR spectra for thermal and ECR plasma oxides are very similar indicating that the same chemical oxide is obtained by both oxidation methods.

\section{XPS results}

In the present study, Ge $3 d$ and $\mathrm{O} 1 \mathrm{~s}$ spectra of germanium oxide were measured. All binding energies were corrected with $\mathrm{C} 1 \mathrm{~s}$ at $285.0 \mathrm{eV}$. The binding energy for elemental $\mathrm{Ge} 3 d$ is $29.1 \mathrm{eV}$ from the literature. ${ }^{30}$ According to Schmeisser, ${ }^{31}$ an average chemical shift per oxidation state for Ge $3 d$ core level is $0.85 \mathrm{eV}$. This means the chemical shift for $\mathrm{GeO}_{2}$ is expected to be $3.40 \mathrm{eV}$ and this is observed. For all the samples we have measured, only elemental Ge and $\mathrm{GeO}_{2}$ were found.

Figures 4(a) and 4(b) show typical XPS spectra of Ge $3 d$ electrons for thermal and ECR plasma oxidation. The two spectra are similar with experimental binding energy and chemical shift $\Delta$ of Ge $3 d$ electrons at different oxidation conditions given in Table III. The Ge $3 d$ electron chemical shift for thermal oxidation is $3.45 \mathrm{eV}$, and a similar value is obtained for ECR plasma oxidation. At $400^{\circ} \mathrm{C} \delta \Delta$ is within

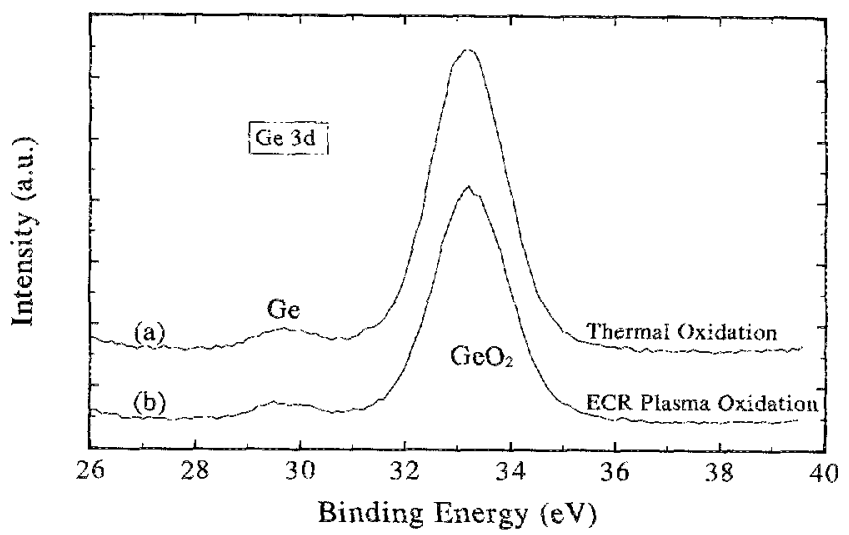

FiG. 4. XPS spectra on Ge $3 d$ electrons for typical (a) thermal oxide at $550^{\circ} \mathrm{C}$; (b) ECR plasma oxide at $+60 \mathrm{~V}$ bias and $400^{\circ} \mathrm{C}$ grown on $c-\mathrm{Ge}$ substrates.

$0.08 \mathrm{eV}$ relative to that of thermal oxidation. The XPS results are in accord with and support our best fit optical model.

\section{$E$. High frequency $C-V$ measurements}

Figure 5 compares high frequency $C-V$ measurements (1 $\mathrm{MHz}$ ) for similar thickness thermal (solid line) and ECR plasma (dashed line) oxides in a Ge MOS structure. Figure 5 (a) shows that a very thin thermal oxide $(3 \mathrm{~nm})$ grown at $400{ }^{\circ} \mathrm{C}$ yields good interfacial properties (oxide charge density is $\sim 10^{10} \mathrm{~cm}^{-2}$ ) but high leakage current as evidenced by the behavior near $C_{\mathrm{ox}}$. The total oxide charge density increases as the thickness of the oxide increases. In all the samples measured, the thinner samples displayed smaller total charge levels (as obtained from the excursion of the $C-V$ trace near flatbands from $\phi_{\mathrm{ms}}$ ), but more leakage current. In comparing the $C-V$ curves of thermal and ECR plasma oxides, it is interesting to note that there is less charge in ECR plasma oxide than in thermal oxide at similar oxide thickness. For the $7 \mathrm{~nm}$ oxide, bumps are seen in the depletion region which are likely due to interface states responding to the $1 \mathrm{MHz}$ test frequency. ${ }^{32}$ More extensive oxidation to thicker oxides removes these states. Our purpose in this study is to determine whether the interface is of reasonable quality and what are the differences if any between thermal and ECR plasma oxides. Both kinds of samples show evidence of inversion with a flat $C_{\text {min }}$ region when ramped from deep depletion. While the thermal oxides almost always

TABIE II. Absorption peak positions for the IR spectra shown in Fig. 3 .

\begin{tabular}{lccc}
\hline Vibration mode & $\begin{array}{c}\text { Absorption peaks }\left(\mathrm{cm}^{-1}\right) \\
\text { in thermal oxide }\end{array}$ & $\begin{array}{c}\text { Absorption peaks }\left(\mathrm{cm}^{-1}\right) \\
\text { in ECR plasma oxide }\end{array}$ & $\begin{array}{c}\text { Absorption peaks }\left(\mathrm{cm}^{-1}\right) \\
\text { from literature }\end{array}$ \\
\hline Ge-O-Ge & 981 & 977 & $820-960,^{\mathrm{a}} \sim 970^{b}$ \\
stretching mode & 859 & 853 & $878,,^{\mathrm{b}} 887^{\mathrm{b}}$ \\
Ge-O-Ge & 563 & 556 & $470-595^{\mathrm{a}}$ \\
bending mode & 521 & 525 & $\sim 500-600^{\mathrm{b}}$ \\
\hline
\end{tabular}

aeference 27.

beference 28 .

${ }^{\mathrm{c}}$ Reference 29. 
TABLE III. XPS binding energy and chemical shifts, $\Delta$, for Ge $3 d$ electrons at different oxidation conditions.

\begin{tabular}{lcccc}
\hline \hline Oxidation conditions & $\begin{array}{c}\text { oxide thickness } \\
\text { (nm) }\end{array}$ & $\begin{array}{c}\text { Binding energy } \\
\text { (Ge 3d, eV) }\end{array}$ & $\begin{array}{c}\text { Chemical shift } \Delta \\
\text { (eV) }\end{array}$ \\
\hline $\begin{array}{l}\text { Thermal } \\
\text { oxidation }\end{array}$ & $550^{\circ} \mathrm{C}, 10 \mathrm{~min}$ & 8 & $29.74,33.19$ & 3.45 \\
ECR plasma & $300^{\circ} \mathrm{C}, 540 \mathrm{~min}$ & 3 & $29.84,33.30$ & 3.46 \\
oxidation & $300 \mathrm{~W}, 400^{\circ} \mathrm{C},+60 \mathrm{~V}$ bias & 8 & $29.71,33.24$ & 3.53 \\
& $300 \mathrm{~W}, 400^{\circ} \mathrm{C},+30 \mathrm{~V}$ bias & 8 & $29.78,33.17$ & 3.39 \\
& $300 \mathrm{~W}, 100^{\circ} \mathrm{C},+60 \mathrm{~V}$ bias & 6 & $29.45,33.06$ & 3.61 \\
\hline
\end{tabular}

showed more total charge near the interface, the thinner thermal oxides were measurable even with leakage while we were unable to perform $C-V$ measurements on ECR plasma oxides that were thinner than $5 \mathrm{~nm}$ due to the high currents. However, in neither case has an effort been made to optimize the processes in terms of interfacial electronic properties; the samples were processed identically except for the oxidations.

\section{DISCUSSION AND CONCLUSIONS}

First it is seen that the XPS and FTIR data confirm that the oxides resulting from thermal and ECR plasma oxidation are the same, namely $\mathrm{GeO}_{2}$. The real time oxidation data and analysis strongly suggest that both thermal and ECR plasma oxidation of Ge follow linear-parabolic kinetics similar to the kinetics proposed for Si thermal oxidation, and both processes display an initially faster regime also similar to $\mathrm{Si}$
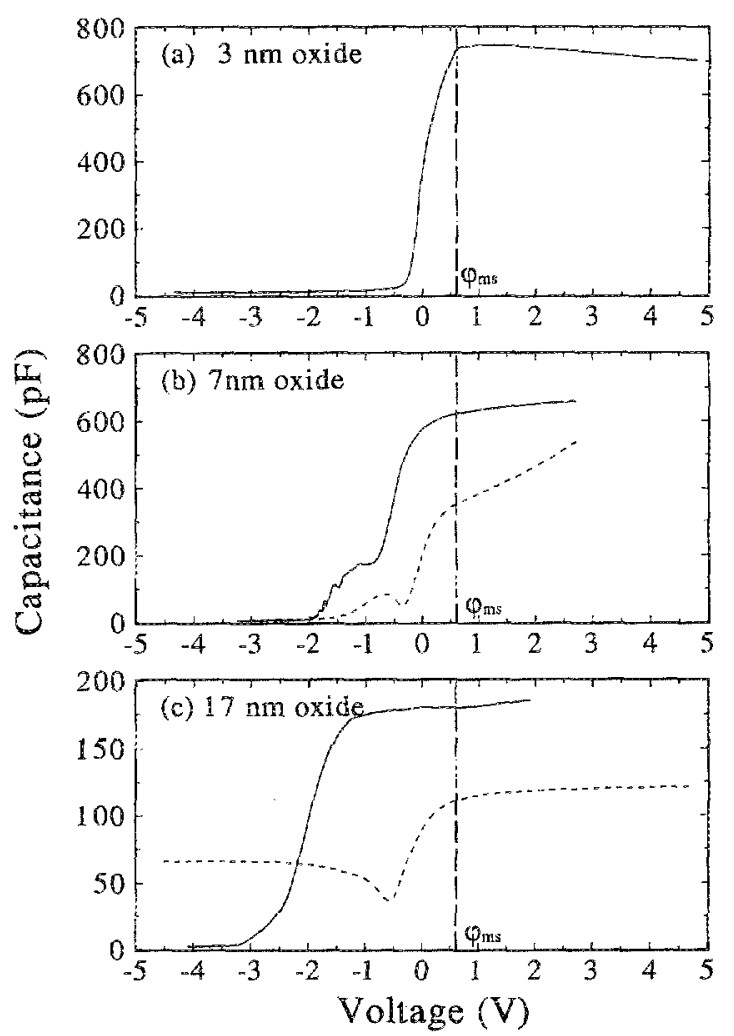

FiG. 5. High frequency $C-V$ measurements ( $1 \mathrm{MHz}$ ) for different oxide thicknesses: (a) 3 nm oxides; (b) 7 nm oxides; (c) $17 \mathrm{~nm}$ oxides. Solid lines are for thermal oxidation and dashed lines for ECR plasma oxidation at +60 $\mathrm{V}$ and $400^{\circ} \mathrm{C}$. oxidation. Our previous studies also showed that both Si and Ge ECR plasma oxidation follow linear-parabolic kinetics, and both display an initial bias independent faster oxidation regime. ${ }^{13}$ This initial regime represents the surface reaction between Ge and the plasma oxidant species for ECR plasma oxidation and molecular oxygen for thermal oxidation. For the ECR plasma oxidation the applied substrate bias greatly affects the oxidation rate after the initial regime and most dramatically when a thicker oxide is formed with positive bias accelerating the rate. ${ }^{13}$ This observation leads to the conclusion that for transport limited growth, negatively charged oxidant species dominate the ECR reaction kinetics. Both thermal and ECR plasma oxication yield temperature activated transport. However, for the ECR plasma oxidation the activation energy is nearly one order of magnitude smaller than for thermal oxidation. This difference can be explained by considering the ECR oxidation via $\mathrm{O}^{-}$species while thermal oxidation is via molecular species as for the thermal oxidation of $\mathrm{Si}^{25}$

The best fit optical models for thermal and ECR oxidation are the same two layer model with the top layer being $\mathrm{GeO}_{2}$ and the interface layer being $a-G e$ plus $\mathrm{GeO}_{2}$. The interesting difference is that for ECR plasma oxidation the interface layer is considerably thinner than for thermal oxidation. In a separate study of the interface region in the $\mathrm{Si}-\mathrm{SiO}_{2}$ system using spectroscopic immersion ellipsometry, ${ }^{33,34}$ we reported that the suboxide layer at the interface increased in thickness as oxidation proceeded, presumably the result of the decreasing oxidant concentration as the overlayer thickens. By analogy to the Ge oxidation system, the rapid transport of $\mathrm{O}^{-}$ species in the ECR process provides a higher oxidant activity at the interface hence a thinner interface region. While further study of this phenomena is warranted and in progress, the smaller interface charge levels observed for ECR plasma oxidation lends further support to this proposition.

\section{ACKNOWLEDGMENTS}

The authors are grateful to W. Ou for XPS measurements and helpful discussions. This work was supported in part by National Science Foundation, NSF and the Office of Naval Research, ONR.

${ }^{1}$ J. Batey and E. Tierney, J. Appl. Phys. 60, 3136 (1986).

${ }^{2}$ G. Lucovsky and D. V. Tsu, J. Vac. Sc. Technol. A 5, 2231 (1987).

${ }^{3}$ A. Sherman, Chemical Vapor Deposition for Microelectronics, edited by R. F. Bunshah (Noyes, Park Ridge, NJ, 1987).

${ }^{4} \mathrm{~S}$. Matsuo, Handbook of Thin Film Deposition and Technique, edited by K. K. Schuegraf (Noyes, Park Ridge, NJ, 1988). 
${ }^{5}$ D. A. Carl, D. W. Hess, M. A. Lieberamn, J. Vac. Sci. Technol. A 8, 2924 (1990).

'D. A. Carl, D. W. Hess, M. A. Lieberamn, T. S. Nguyen, and R. Gronsky, J. Appl. Phys. 70, 3301 (1991).

${ }^{7}$ G. T. Salbert, D. K. Reinhard, and J. Asmussen, J. Vac. Sci. Technol. A 8, $2919(1990)$.

${ }^{8}$ Y. Z. Hu, J. Joseph, and F. A. Irene, Appl. Phys. Lett. 59, 1353 (1991).

${ }^{9}$ J. J. Rosenberg and S. C. Martin, JEEE Trans. Electron. Device Lett. EDL_9, 639 (1988).

${ }^{10} \mathrm{Q}$. Hua, Y. J. Rosenberg, J. Ye, and E. S. Yang, J. Appl. Phys. 53, 8969 (1982).

${ }^{11}$ D. J. Hymes and J. J. Rosenberg, J. Electrochem. Soc. 135, 961 (1988).

${ }^{12}$ Y. Z. Hu, J.-Th. Zettler, S. Chongsawangvirod, Y. Wang, and E. A. Irene, Appl. Phys. Lett. 61, 1098 (1992).

${ }^{13}$ Y. Z. Hu, Y. Wang, M. Li, J. Joseph, and E. A. Irene, J. Vac. Sci. Technol. A 11, 900 (1993).

${ }^{14}$ J. W. Andrews, Y. Z. Hu, and E. A. Irene, Proc. SPIE 1118, 162 (1990).

${ }^{15} \mathrm{~J}$. W. Andrews, Ph.D. thesis, University of North Carolina at Chapel Hill, 1990.

${ }^{16}$ D. E. Aspnes, and A. A. Studna, Appl. Phys. Lett. 39, $316(1981)$.

${ }^{17}$ J. Joseph, Y. 7. Hu, and E. A. Irene, J. Vac. Sci. Technol. B 10, 611 (1992).
${ }^{18}$ A. Gagnaire, J. Joseph, and A. Etcheberry, J. Flectrochem. Soc. 134, 2476 (1987).

${ }^{19}$ F. A. Irene, Thin Solid Films 223, 96 (1993).

${ }^{20}$ J.-Th. Zettler, M. Weidner, and A. Roseler, Phys. Status Solidi A 124, 547 (1991).

${ }^{21}$ J. C. Poler, Ph.D. thesis, University of North Carolina, Chapel Hill, NC, 1992.

22D. E. Aspens, J. B. Theeten, and F. Hottier, Phys. Rev. B 20, 3992 (1979).

${ }^{23} \mathrm{~F}$. A. Lewis and E. A. Trene, J. Vac. Sci. Technol. A 4, 916 (1986).

${ }^{24}$ B. E. Deal and A. S. Grove, J. Appl. Phys. 36, 3770 (1965).

${ }^{25}$ E. A. Irene, CRC Crit. Rev. Solid State Mater. Sci. 14, 175 (1988).

${ }^{26}$ N. Cabrera and N. F. Mott, Rep. Prog. Phys. 12, 163 (1948).

${ }^{27}$ B. T.-K. Chen and G.-J. Su, Phys. Chem. Glass. 12, 33 (1971).

${ }^{28}$ M. K. Murthy and E. M. Kirby, Chem. Glass 5. 144 (1964).

${ }^{29}$ W. Kaiser, P. H. Keck, and C. F. Lange, Phys. Rev. 101, 264 (1956).

${ }^{30} \mathrm{G}$. Hollinger, P. Kumurdjian, J. M. Mackowski, P. Pertosa, L. Porte, and

T. M. Due, J. Electron. Spectrose. Relat. Phenom. 5, 237 (1974),

${ }^{31}$ D. Schmeisser, R. D. Schnell, A. Bogen, F. J. Himpsel, D. Rieger, G. Landgren, and J. F. Morar, Surf. Sci. 172, 455 (1986).

${ }^{32}$ T. J. Mego, Solid State Technol. 159 (May, 1990).

${ }^{33} \mathrm{Q}$. Liu and F. A. Irene, Mater. Res. Soc. Symp. Proc. 315, 405 (1993).

${ }^{34}$ Q. Liu, J. F. Wall, and E. A. Irene, J. Vac. Sci. Technol. B (submitted). 